\title{
We will continue to grow up together!
}

\section{Laura Evangelista ${ }^{1}$}

Published online: 12 August 2020

(c) Italian Association of Nuclear Medicine and Molecular Imaging 2020

I am humbled and excited about this new role. It is a big responsibility, but I have had an excellent mentoring: Prof. Giovanni Lucignani. Moreover, the outstanding composition of the Editorial Board, and the competent and helpful staff of Springer will render this work simple to perform. Since becoming a deputy editor in 2017, I have long been aware of the high-quality research this journal promotes and disseminates, and of its important role in supporting the nuclear medicine specialists and all specialties connected with it.

My goal during my call as Editor in Chief of the Clinical and Translational Imaging will be to further increase its visibility in our research community, and to attract more submissions from all experts worldwide. However, I need your help to continue the growth of the journal. Moreover, I ask for a great effort from the youngest. They can highly support the development of the journal, with their curiosity and great enthusiasm.

I would like to thank the Italian Association of Nuclear Medicine (AIMN) for giving me this opportunity to support the journal and for providing the worldwide diffusion of
Nuclear Medicine and molecular imaging information. Now, all together, we have to look into the future and to go beyond without stopping us. Clinical and Translational Imaging journal should be continued to be a teaching instrument, enriched by many collections of images, by systematic or expert reviews, by spotlight and editorials. However, some news will be implemented in the next year.

I conclude by inviting you to join me in my efforts to make Clinical and Translational Imaging the best possible tool for all specialists in nuclear medicine and molecular imaging. I am ready to start working with all of you to bring Clinical and Translational Imaging to new levels of success and scientific impact.

Laura Evangelista

Editor-in-Chief

Publisher's Note Springer Nature remains neutral with regard to jurisdictional claims in published maps and institutional affiliations.
Please do also note the editorial "New Challenges for the Clinical and Translational Imaging Journal" from "Orazio Schillaci, President of the Italian Association of Nuclear Medicine (AIMN)", https://doi.org/10.1007/s40336-020-00381-1.

Laura Evangelista

laura.evangelista@unipd.it

1 Nuclear Medicine Unit, Department of Medicine (DIMED), University of Padua, Padua, Italy 